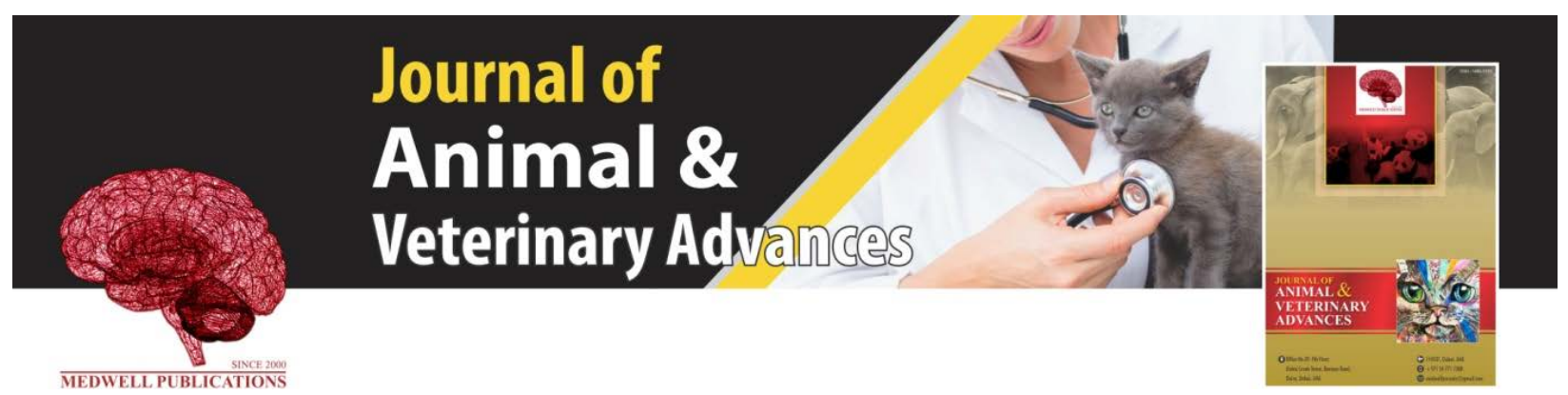

\title{
Evaluation of Sexual Behavior of Stallion (Arabian Versus Barb) in Algeria
}

\author{
${ }^{1,2}$ Hind Houssou, ${ }^{1,2}$ Farida Bouzebda-Afri and ${ }^{1,2}$ Zoubir Bouzebda \\ ${ }^{1}$ Department of Veterinary Sciences, Institute of Agronomy and Veterinary Science, University of Souk- \\ Ahras, Souk-Ahras, Algeria \\ ${ }^{2}$ Laboratory of Animal Productions, Biotechnologies and Health, Institute of Agronomic and Veterinary \\ Sciences, Souk-Ahras University, Souk-Ahras, Algeria
}

Key words: Algeria, sexual behavior, libido, stallion, animal management, Arabian and Barb

\section{Corresponding Author: \\ Hind Houssou}

Department of Veterinary Sciences, Institute of Agronomy and Veterinary Science University of Souk-Ahras, Souk-Ahras, Algeria

Page No.: 278-283

Volume: 18, Issue 9, 2019

ISSN: $1680-5593$

Journal of Animal and Veterinary Advances

Copy Right: Medwell Publications
Abstract: This study was carried out in national Stud in Tiaret West of Algeria to understand and to evaluate the normal sexual behavior and libido of stallions (Arabian vs. Barb) while mounting a mare in estrus. Eighty-four stallions were divided to two groups from 5-24 years age ( $n=47$ Arabian; $n=37$ Barb). Results revealed significant differences $(\mathrm{p}<0.05, \mathrm{p}<0.01, \mathrm{p}<0.001)$ in sniffing, libido score, flehmen response; time to first mount with erection, number of mounts to ejaculation and mount time for ejaculatory reaching a mean value of $(19.15 \pm 10.76 ; 12.23 \pm 2.68 ; \mathrm{p}<0.01)$ second respectively for Arabian an Barb stallion. These stallions were tested in exactly the same place and conditions allows us to discard any side effects due to animal management or any other confounding bias. Our study provided us the knowledge of sexual behavior under Algerian conditions and the distinction between Arabian and Barb stallion.

\section{INTRODUCTION}

Horses are seasonal mammals with a breeding season occurring during long days under natural conditions in the northern hemisphere (Salazar-Ortiz et al., 2011). The mating is natural during the officially Algerian breeding season, starting from 15 February to 15 June (National Stud of Chaouchaoua Tiaret, West of Algeria). Ethology is a subdiscipline of animal behavior science that focuses on the study of the behavior of animals as it evolved under natural conditions (McDonnell, 2016).

The external manifestations of sexual behavior rare said to be characteristic of the species. For maximum reproductive efficiency, stallions have to be managed to maintain normal sexual behavior and good libido (Pickett et al., 1975). To maximize the reproduction efficiency of stallions, they should be handled frequently to maintain adequate sexual behavior and good libido (Sieme et al., 2004).

Typically, a stallion with good libido shows immediate and intense desire for the mare, manifested by pawing and vocalization. The onset, intensity and duration of this courtship phase are affected by the stallion's genetic makeup, learned behavior (through both positive The onset, intensity and duration of this courtship phase are affected by the stallion's genetic makeup, learned behavior (through both positive and negative experiences), seasonal variation and disease. A common cause for reduced or arrested libido in stallions is mismanagement and negative experiences), seasonal variation and disease. A common cause for reduced or arrested libido in stallions is mismanagement, especially 
overuse or repetitive abusive punishment for expression of sexual interest (McDonnell, 1992; Blanchard et al., 2002). Especially, overuse or repetitive abusive punishment for expression of sexual interest (McDonnell, 1992; Blanchard et al., 2002).

The age not affect the sexual behavior (Flehmen, number of bites, kicks, sniffs, vocalizations reaction time, mount time and ejaculation time) or libido in stallions (Rua et al., 2015). This study begin by the description of the sexual behavior in order to explain their stages, to illustrate their usefulness and understand the basic ethology of behavior science stallions concepts in order to provide valuable insight into the most of the common breeding behavior problems.

\section{MATERIALS AND METHODS}

Data location: The study was conducted at the National Stud of Chaouchaoua Tiaret. This province is located in the West of Algeria and it characterized by a continental climate with harsh winter and hot and dry summer and the rainfall of 300-400 mm/year on average a latitude of $35^{\circ} 15^{\prime} \mathrm{N}$ and a longitude of $1^{\circ} 26^{\prime} \mathrm{E}$. The Stud, created in 1877, on surface of 800 ha it totals number of 250 horses, composed by two main races (Arabian and Barb).

Study population: The study was carried during four consecutive breeding season between March and May (2012-2015). The number chosen based on the availability of breeding animals. Eighty-four stallions were utilized in the development of the sexual behavior parameters about Arabian ( $n=47$; age range: $05-24$ years) and Barb ( $n=37$; age range: 05-24 years).

The Body Weight (BW): Was done as per work on the Algerian horse population and other works worldwide.

The Body Condition Score (BCS): Was based on visual appraisal and palpable fat cover at six areas of the horse's body and was evaluated on a scale of 1-9. Henneke et al. (1983) give a description of the condition score system.

Precopulatory phase: The stallion typically approaches a mare in a prancing gait with arched neck and raised tail. Reaction time was recorded beginning when the stallion entered the breeding facility and ending when the stallion mounted a mare in estrus (McDonnell and Murray, 1995; McDonnell, 2000; Noue et al., 2001; Cavinder et al., 2010; Najjar et al., 2010).

Photographs of sexual behavior have been taken as part during precopulatory sequences and were presented in Fig. 1-5. Time to erection, time to first mount with erection and number of mounts to ejaculation were

(a)

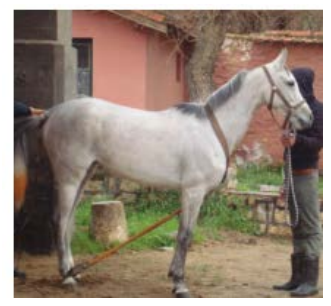

(b)

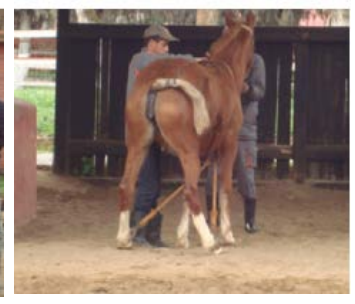

Fig. 1: Posture of mare in estrus

(a)

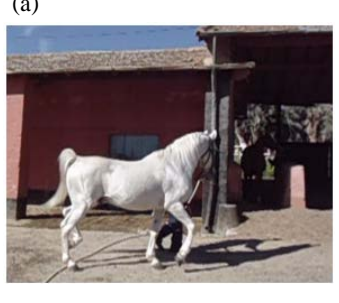

(c)

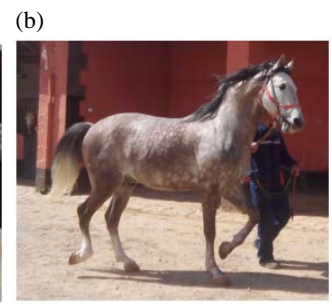

(b)

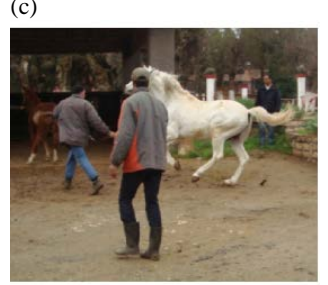

Fig. 2: Stallion-typical approach posture and gait (a)

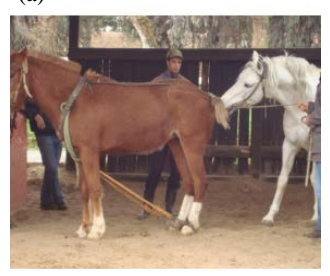

(b)

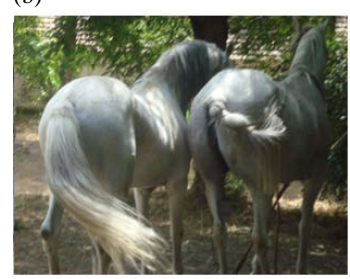

(c)

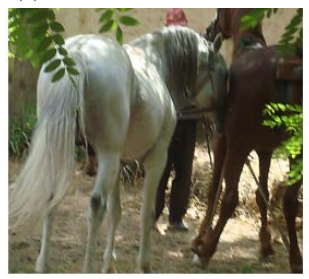

Fig. 3: Stallion detect the receptivity of mare

recorded. To quantify the intensity of sexual arousal, 2 individual appraisers assigned libido scores (Table 1) to each stallion when presented with an estrous mare. (Cavinder et al., 2010).

Copulatory phase: The copulatory event commences with a quiet approach of the pair includes mounting, 
Table 1: Libido score description (Cavinder et al., 2010)

\begin{tabular}{ll}
\hline Scores & Description \\
\hline 0 & No interest in an estrous mare \\
1 & Slight vocalization and interest initially but quickly fades \\
2 & $\begin{array}{l}\text { Moderate vocalization and interest in mare but interest } \\
\text { dissipates }\end{array}$ \\
3 & $\begin{array}{l}\text { Moderately interested and consistent contact with mare } \\
\text { Highly interested with vocalization and squealing; consistent } \\
\text { contact or attempt to mount }\end{array}$ \\
\hline
\end{tabular}

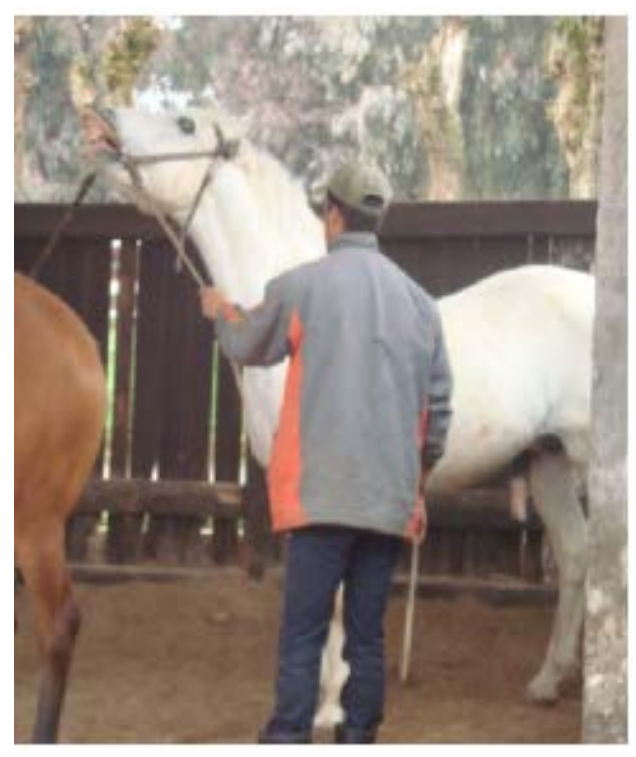

Fig. 4: The flehmen

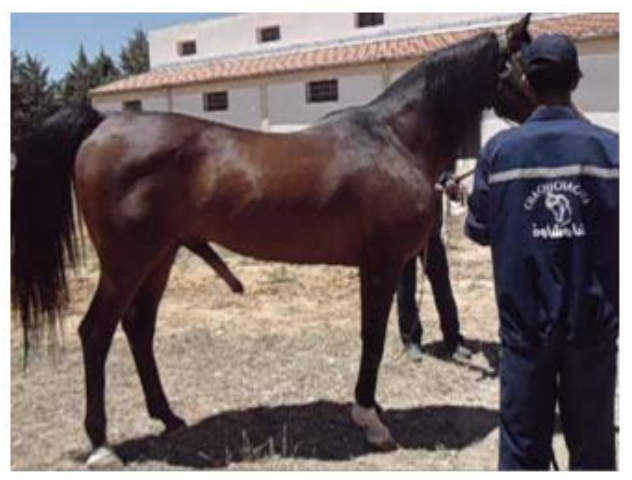

Fig. 5: Stallion in erection
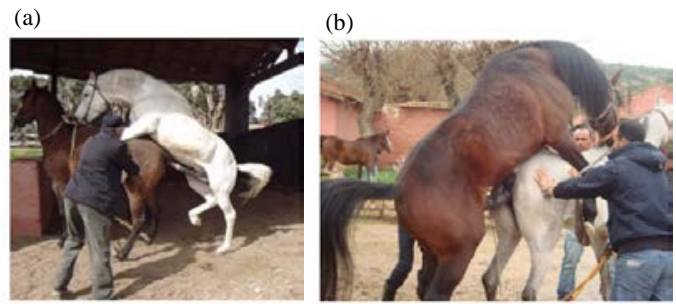

Fig. 6: Mounting position and copulation insertion, thrusting, ejaculation and dismount (Fig. 6). The number of mounts required before ejaculation and the reaction time for each stallion were recorded. The sexual behavior sequences have been described in detail by McDonnell (2016).

Data analysis: Data were analyzed using SPSS 20 and expressed as the mean \pm Standard Error of Mean (SEM) 55454 min and max. Data collected were subjected to various statistical tools in a one-way analysis of variance followed by the Student Newman-Keuls multiple comparison test was used to study the effect of race on sexual behavior and libido score. Differences with values of $(\mathrm{p}<0.05, \mathrm{p}<0.01, \mathrm{p}<0.001)$ were considered to be statistically significant.

\section{RESULTS AND DISCUSSION}

Stallion's data: Table 2 presents the results of the mean age of stallion ( $15.55 \pm 4.62$ vs. $15.08 \pm 4.85)$, respectively for Arabian and Barb stallion ( $>0.05$ ). The Body Condition Score (BCS) system developed for broodmares can be utilized to evaluate the condition of stallions (Henneke et al., 1983). Routine evaluation of stallion's body condition can be an effective tool for determining if we have underfeeding or overfeeding stallion. The mean of BCS, respectively for Arabian and Barb stallions (5.02 \pm 0.21 vs. $5.30 \pm 0.24)$ and the weight ( $367 \pm 30.38$ vs. $374 \pm 33.59)$ are not significant $(\mathrm{p}>0.05)$ during experience and under the same feeding programs (Table 2).

Research has shown that nutrition plays an important role in the reproductive performance of various species. According to Gentry et al. (2004), Mantovani and Bailoni (2011) a minimum level of body condition is needed to ensure adequate reproductive activity in stallions. Perkins et al. (1985) and Burkholder (2000) reported that the body condition could also have an influence on the animal's productivity and health as well as reproduction.

Behavioral analysis: The ability of a stallion to copulate normally should be assessed before the stallion is considered to be a satisfactory prospect for breeding (Blanchard et al., 2011). Key elements of stallion behavior (Arabian and Barb) are listed in Table 3. The cyclic behavioral patterns observed in the stallions in this study were similar to those described by other researchers (McDonnell, 1986; Cavinder et al., 2010; Guillaume et al., 2018).

Libido score: Libido Assessment traits were quantified for stallions with a mare estrous on scale of 0-4 the one described by Cavinder et al. (2010). The mean value of libido score (3.07 \pm 0.66 vs. $3.67 \pm 0.76$ ), respectively for Arabian and Barb stallions present a significant difference 
J. Anim. Vet. Adv., 18 (9): 278-283, 2019

Table 2: Descriptive statistics of the age, weight and BCS of stallions

\begin{tabular}{lcccccrr}
\hline Variables & Races & $\mathrm{N}$ & Mean & SD & Min. & Max. & p-values \\
\hline Age & 1 & 47 & 15.55 & 4.62 & 5.00 & 24.00 & 0.537 \\
& 2 & 37 & 15.08 & 4.85 & 5.00 & 24.00 & 6.00 \\
BCS & 1 & 47 & 5.02 & 0.21 & 4.00 & 6.00 & 0.650 \\
\multirow{2}{*}{ Weight $(\mathrm{kg})$} & 2 & 37 & 5.30 & 0.24 & 314 & 412 & 0.174 \\
& 1 & 47 & 367 & 30.38 & 376 & 426 \\
\hline
\end{tabular}

BCS: Body Condition Score; N: Number of stallions; 1: Arabian race; 2: Barb race, not significant at p>0.05

Table 3: Descriptive statistics of the quantitative sexual behavior of Stallions (Arabian and Barb)

\begin{tabular}{|c|c|c|c|c|c|c|c|}
\hline Variables & Races & $\mathrm{N}$ & Mean & SD & Min. & Max. & p-values \\
\hline \multicolumn{8}{|l|}{ Precopulatory phase } \\
\hline \multirow[t]{2}{*}{ Libido score } & 1 & 47 & 3.07 & 0.66 & 1.00 & 4.00 & $0.045^{*}$ \\
\hline & 2 & 37 & 3.67 & 0.76 & 2.00 & 4.00 & \\
\hline \multirow[t]{2}{*}{ Sniffing } & 1 & 47 & 6.54 & 3.78 & 2.00 & 15.00 & $<0.001^{* * *}$ \\
\hline & 2 & 37 & 16.85 & 7.47 & 6.00 & 30.00 & \\
\hline \multirow[t]{2}{*}{ Flehmen response } & 1 & 47 & 1.61 & 1.38 & 0.00 & 4.00 & $0.033^{*}$ \\
\hline & 2 & 37 & 2.48 & 1.57 & 0.00 & 7.00 & \\
\hline \multirow[t]{2}{*}{ Biting } & 1 & 47 & 1.33 & 1.27 & 0.00 & 5.00 & 0.057 \\
\hline & 2 & 37 & 0.84 & 0.98 & 0.00 & 2.00 & \\
\hline \multirow[t]{2}{*}{ Time to erection (sec) } & 1 & 47 & 48.70 & 56.20 & 8.0 & 245 & 0.940 \\
\hline & 2 & 37 & 50.38 & 20.15 & 17.00 & 80.00 & \\
\hline \multirow[t]{2}{*}{ Time to first mount with erection (sec) } & 1 & 47 & 112 & 58.90 & 29.0 & 365 & $0.020^{*}$ \\
\hline & 2 & 37 & 90.54 & 33.17 & 47.00 & 180 & \\
\hline \multicolumn{8}{|l|}{ Copulatory phase } \\
\hline \multirow[t]{2}{*}{ Number of mounts to ejaculation } & 1 & 37 & 2.00 & 1.00 & 1.00 & 5.00 & $0.029 *$ \\
\hline & 2 & 37 & 1.46 & 0.51 & 1.00 & 2.00 & \\
\hline \multirow[t]{2}{*}{ Mount time for ejaculatory mount (sec) } & 1 & 47 & 19.15 & 10.76 & 8.00 & 65.00 & $0.005 * *$ \\
\hline & 2 & 37 & 12.23 & 2.68 & 9.00 & 17.00 & \\
\hline \multirow[t]{2}{*}{ Total time in breeding area (sec) } & 1 & 47 & 218 & 18.24 & 75 & 710 & 0.373 \\
\hline & 2 & 37 & 169 & 55.80 & 69 & 247 & \\
\hline
\end{tabular}

$\mathrm{N}$ : Number of stallions; 1 : Arabian race; 2 : Barb race, sec: seconds; ${ }^{*}$ Significant at $\mathrm{p}<0.05$; ${ }^{* *}$ Significant at $\mathrm{p}<0.01$; ${ }^{* * *}$ Significant at $\mathrm{p}<0.001$

$(\mathrm{p}<0.05)$. The mean libido score for Arabian stallions similar to (3.15 \pm 0.87$)$ reported by Cavinder et al. (2010) in contrast, the Barb stallion present a higher libido score. In breeding season, horses use various sensory cues to assess the reproductive status of their sexual partner such as auditory, visual or olfactory cues (Stahlbaum et al., 1989; Crowell-Davis, 2007).

Sniffing and flehmen frequency: To our knowledge, no study has correlated scent marking by stallions through defecation and urination with olfactory information obtained by those stallions from faecal odour concerning the sex and reproductive status of faecal sample donors (Jezierski et al., 2017).

Studies on equine olfaction have concentrated primarily on the role of pheromones in mating behaviour (Saslow, 2002). All stallions were immediately interested in the olfactory stimulus and expressed sniffing behavior. Once stimulated with urinary odors, sniffing was immediately followed by the expression of flehmen. It is of interest that during the expression of flehmen, stallions produce a few milliliters of nasal secretion as previously described by Lindsay and Burton (1983) and Guillaume et al. (2018).

The total frequency of sniffing and flehmen behaviors as well as the number of flehmen responses are shown in Table 3. These results were in agreement with those reported by Mcdonell (1986), Mcdonell (1992) and Guillaume et al. (2018) for "normal” stallions. There are significant difference $(\mathrm{p}<0.001)$ presented in Table 3 between the sniffing score of Arabian and Barb stallion. There is significant difference $(p<0.05)$ between Arabian and Barb stallion in flehmen frequency. The stallion with the highest libido sniffed faeces significantly longer than was true for other stallions (Jezierski et al., 2017).

Precopulatory and copulatory sequences: Most of these stallions exhibited some precopulatory interaction, achieved a full erection within 1 min and mounted within 1 or 2 min after erection similar findings also reported by many researchers such as McDonnell $(1986,1992)$ and Guillaume et al. (2018).

According to McDonnell (2000) in most directed mounts, the stallion is usually not allowed to mount the mare without erection because it is understood that when the stallion spends less time mounting the mare, the risk of injury to either the animal or handler guiding the procedure is reduced.

A copulatory interaction, from approach to ejaculation, often occurs in a period of less than one minute is similar to the values reported by McDonnell (1986); mount time for ejaculatory (19.15 \pm 10.76 ; 12.23 \pm 2.68$)$, respectively of Arabian and Barb stallion present a significant difference $(\mathrm{p}<0.01)$. 


\section{CONCLUSION}

Our study was taken to provide us the knowledge of sexual behavior under Algerian conditions and the distinction between Arabian and Barb stallion. The hope for the future studies in the following:

- Knowledge of sexual function and dysfunction disorders with during the breeding season

- Greater use of routine sexual behavior assessment of stallions in an effort to establish characteristic patterns for each stallion while he is fertile

\section{ACKNOWLEDGEMENT}

The researchers are thankful to the director of National Stud of Chaouchoua Tiaret and Haddouche zohra (veterinarian manager) for providing facilities and help throughout the period of the research.

\section{REFERENCES}

Blanchard, T., D. Varner, C. Love, S. Brinsko, S. Rigby and J. Schumacher, 2002. Manual of Equine Reproduction. 2nd Edn., Mosby, Missouri, USA., ISBN: 9780323017138, Pages: 272.

Burkholder, W.J., 2000. Use of body condition scores in clinical assessment of the provision of optimal nutrition. J. Am. Vet. Med. Assoc., 217: 650-654.

Cavinder, C.A., J.L. Zoller, G. Briers and D.H. Sigler, 2010. Sexual behavior and blood hormone profiles around the time of ejaculation and subsequent sperm characteristics in stallions. Prof. Anim. Sci., 26: 540-546.

Crowell-Davis, S.L., 2007. Sexual behavior of mares. Hormones Behav., 52: 12-17.

Gentry, L.R., D.L. Thompson Jr, G.T. Gentry Jr, R.P.D. Vecchio, K.A. Davis and P.M.D. Vecchio, 2004. The relationship between body condition score and ultrasonic fat measurements in mares of high versus low body condition. J. Equine Vet. Sci., 24: 198-203.

Guillaume, D., C. Moussu, F.D. Geoffroy, D. Chesneau and M. Keller, 2018. Olfactory stimulation or inhibition of sexual behavior of stallions in non-breeding season. Physiol. Behav., 186: 1-9.

Henneke, D.R., G.D. Potter, J.L. Kreider and B.F. Yeates, 1983. Relationship between condition score, physical measurements and body fat percentage in mares. Equine Vet. J., 15: 371-372.

Jezierski, T., Z. Jaworski, M. Sobczynska, J. Ensminger and A. Gorecka-Bruzda, 2018. Do olfactory behaviour and marking responses of Konik polski stallions to faeces from conspecifics of either sex differ?. Behav. Processes, 155: 38-42.
Lindsay, F.E. and F.L. Burton, 1983. Observational study of "urine testing" in the horse and donkey stallion. Equine. Vet. J., 315: 330-336.

Mantovani, R. and L. Bailoni, 2011. Energy and protein allowances and requirements in stallions during the breeding season, comparing different nutritional systems. J. Anim. Sci., 89: 2113-2122.

McDonnell, S., 1986. Reproductive behavior of the stallion. Vet. Clin. North Am. Equine Pract., 2: 535-555.

McDonnell, S.M. and S.C. Murray, 1995. Bachelor and harem stallion behavior and endocrinology. Biol. Reprod., 1: 577-590.

McDonnell, S.M., 1992. Normal and abnormal sexual behavior. Vet. Clin. North Am. Equine Pract., 8: 71-89.

McDonnell, S.M., 2000. Reproductive behavior of stallions and mares: Comparison of free-running and domestic in-hand breeding. Anim. Reprod. Sci., 60: 211-219.

McDonnell, S.M., 2016. Revisiting clinical stallion sexual behavior: Applying ethology in the breeding shed. J. Equine Vet. Sci., 43: S18-S22.

Najjar, A., B. Benaoun, M. Ezzaouia, A.B. Maatoug, M. Magistrini and M.B. Mrad, 2010. Determination of semen and sexual behavir parameters of Arabian stallions to be selected for an Artificial Insemination program under Tunisian conditions. Am. Eurasian J. Agric. Environ. Sci., 8: 173-177.

Noue, P., J. Bernabe, O. Rampin, M. Vidament, T. Dumas, E. Palmer and M. Magistrini, 2001. Sexual behavior of stallions during in-hand natural service and semen collection: An observation in French studs. Anim. Reprod. Sci., 68: 161-169.

Perkins, B.L., R.D. Smith and C.J. Sniffen, 1985. Body condition scoring: A useful tool for dairy herd management. Cornell Cooperative Extension Dairy Management Fact Sheet, Ithaca, Cornell University, Ithaca, New York, USA.

Pickett, B.W., J.J. Sullivan and G.E. Seidel, 1975. Reproductive physiology of the stallion. V. Effect of frequency of ejaculation on seminal characteristics and spermatozoal output. J. Anim. Sci., 40: 917-923.

Rua, M.A.S., C.R. Quirino, R. Bastos, A.B. Junior and P.N. Santoro et al., 2015. Evaluation of the sexual behavior and testosterone concentrations of Mangalarga Marchador stallions. Applied Anim. Behav. Sci., 171: 101-107. 
Salazar-Ortiz, J., S. Camous, C. Briant, L. Lardic, D. Chesneau and D. Guillaume, 2011. Effects of nutritional cues on the duration of the winter anovulatory phase and on associated hormone levels in adult female Welsh pony horses (Equus caballus). Reprod. Biol. Endocrinol., Vol. 9, 10.1186/1477-7827-9-130

Saslow, C.A., 2002. Understanding the perceptual world of horses. Applied Anim. Behav. Sci., 78: 209-224.
Sieme, H., T. Katila and E. Klug, 2004. Effect of semen collection practices on sperm characteristics before and after storage and on fertility of stallions. Theriogenology, 61: 769-784.

Stahlbaum, C.C. and K.A. Houpt, 1989. The role of the flehmen response in the behavioral repertoire of the stallion. Physiol. Behav., 45: 1207-1214. 